\title{
Conciencia canónica de Pablo en la Primera Carta a los Tesalonicenses
}

\author{
Andrés Ferrada \\ PONTIFICIA UNIVERSIDAD CATÓLICA DE CHILE
}

\section{INTRODUCCIÓN}

La conciencia canónica ${ }^{1}$ dice relación a cómo la comunidad eclesial ha captado la sacralidad y normatividad de las Escrituras. En efecto, según el Magisterio el canon de las Sagradas Escrituras es ante todo la regla, norma o lista autorizada de aquellos libros que la Iglesia recibe y usa como sagrados, porque escritos por inspiración del Espíritu Santo, tienen a Dios como autor.

Las verdades reveladas por Dios, que se contienen y manifiestan en la Sagrada Escritura, se consignaron por inspiración del Espíritu Santo. La santa Madre Iglesia, según la fe apostólica, tiene por santos y canónicos los libros enteros del Antiguo y del Nuevo Testamento con todas sus partes, porque, escritos bajo la inspiración del Espíritu Santo (cf. Jn., 20, 31; 2 Tim., 3, 16; 2 Pe., 1, 19-20; 3, 15-16), tienen a Dios como autor, y como tales se le han confiado a la misma Iglesia [...]. (Dei Verbum 11).

Ahora bien, debe notarse que el canon comprende dos aspectos: uno pasivo, la lista de escritos, y otro activo, la normatividad del contenido de los libros para la vida de los creyentes.

En cuanto al primer aspecto el proceso de reconocimiento, esto es, la lista de libros sagrados, tiene una historia teológica y magisterial que

El término y la doctrina fue tomada de A. A. Artola - J. M. Sánchez Caro, "Formación de una conciencia canónica en la Escritura», en Biblia y Palabra de Dios, (Estella $\left.{ }^{4} 1995\right)$ 74-82. Original 1989. Cf. M. A. Ferrando, Iniciación a la lectura de la Biblia. Formación, Transmisión e Interpretación, (Santiago ${ }^{6} 2004$ ) 136139. Original 1976. 
es posible estudiar pormenorizadamente ${ }^{2}$. El final de este proceso en la Iglesia Católica tuvo lugar con la definición dogmática de la lista de los libros sagrados, de uno y otro testamento, en la cuarta sesión del Concilio de Trento (8 de abril de 1546; DH 1501-1508). Esa declaración eclesial, con todo, se inserta en su Tradición viva (cf. Dei Verbum 8). En efecto, el criterio usado para la definición fue precisamente el uso litúrgico de los escritos: «[...] y si alguno no recibiera como sagrados y canónicos los libros mismos íntegros con todas sus partes, tal como se han acostumbrado leer en la Iglesia Católica [...]». (DH 1504).

Ahora bien, llegar a esa formulación supuso la toma de conciencia eclesial de la sacralidad y normatividad de los escritos que se contienen en la Biblia. A ese proceso se lo denomina generalmente «formación del canon $»^{3}$. En su estudio, los manuales introductivos suelen distinguir la formación del canon de uno y otro testamento. Respecto del Nuevo Testamento ${ }^{4}$, por tanto, la formación del canon corresponde a ese proceso eclesial respecto de ciertos escritos cristianos primitivos. Aquí entendemos "conciencia» simplemente como el «conocimiento exacto y reflexivo de las cosas» ${ }^{5}$.

\section{Conciencia Canónica en el Nuevo Testamento}

La historia de la formación del canon del Nuevo Testamento se remonta a Jesús de Nazaret que se auto-presenta como el Mesías anunciado por las tradiciones de Israel, particularmente aquellas recogidas en los escritos que los cristianos llamamos el Antiguo Testamento; pero también como Hijo de Dios que reconcilia a la humanidad con el Padre -de quien Jesús es Hijo desde siempre- y los eleva a la calidad de hijos adoptivos de ese mismo Padre, haciéndolos sus hermanos por gracia. Esta reconciliación la lleva a cabo a través de palabras y gestos íntimamente conexos entre sí y, una vez resucitado de entre los muertos, enviando al

2 Cf. M. A. Ferrando, Iniciación; V. Mannucci, La Biblia como Palabra de Dios. Introducción general a la Sagrada Escritura (Bilbao ${ }^{9} 1995$ ) 183-209. Original italiano 1985; A. A. Artola - J. M. SÁnchez Caro, Biblia... , 83-132.

3 Cf. M.A. Ferrando, Iniciación...; V. Mannucci, La Biblia..., 183-209; A. A. Artola - J. M. Sánchez Caro, Biblia..., 83-132.

4 Cf., por ejemplo, A. A. Artola - J. M. Sánchez Caro, Biblia... , 92-100.

5 Tercera acepción dada al término por RAE, Diccionario de la Lengua Española (Madrid 1992) 530. 
Espíritu Santo para continuar su presencia entre sus discípulos y prolongar su obra de salvación en el mundo hasta el final de los siglos. En este contexto pascual, Jesús resucitado envía a sus apóstoles y discípulos a hacer discípulos suyos a todas las gentes, bautizándolos y enseñándoles a guardar todo lo que Él les había mandado (cf. Mc 16,20; Mt 28,19-20) .

La necesidad de conservar esta predicación en su frescura original y evitar distorsiones en su enseñanza, llevó a los apóstoles y a otras personas de su generación, bajo la inspiración del Espíritu Santo, a poner por escrito esta tradición, que normalmente se denomina tradición apostóli$\mathrm{ca}^{7}$. Estos escritos fueron considerados «regla de la fe» por los cristianos desde el inicio ${ }^{8}$.

La "conciencia canónica» queda de manifiesto en algunos textos de autores neo-testamentarios ${ }^{9}$, como, por ejemplo, el evangelista Lucas en el prólogo de su obra:

${ }^{1}$ Puesto que muchos han intentado narrar ordenadamente las cosas que se han verificado entre nosotros, ${ }^{2}$ tal como nos las han transmitido los que desde el principio fueron testigos oculares y servidores de la Palabra, ${ }^{3}$ he decidido yo también, después de haber investigado dili-

6 Cf. Dei Verbum 4.

7 Cf. Dei Verbum 7 y 8.

8 Será la cristalización posterior de la doctrina, principalmente en la controversia contra diversas corrientes gnósticas. Como los gnósticos fundaban sus ideas en textos bíblicos, san Ireneo de Lyon se dio cuenta de que no podía resolver las divergencias que tenía con ellos recurriendo a un principio hermenéutico interno a la misma Escritura. Debía recurrir a una regla externa que asegurara que la interpretación de un pasaje bíblico fuera correcta. Esta norma no podía ser otra sino la regla de la fe, esto es, la confesión de fe emitida en el bautismo y transmitida por tradición (Adv. Haer. 1, 10,1). La regla de la fe por sí misma no explica la Escritura, pero ofrece el marco dentro del cual tiene que mantenerse toda exégesis para no caer en error en sus conclusiones. Los padres seguirán este rumbo. Por ejemplo, Agustín afirma que no creería en el evangelio si no lo atestiguase la Iglesia (PL 42,176). Ahora bien, para conocer dónde estaba esta tradición se debía remontar hasta los orígenes apostólicos, y el camino más breve para hacerlo era interrogar a la Iglesia de Roma, la cual, debido a la sucesión episcopal ininterrumpida y a la confluencia de todos los pueblos, mantuvo la pureza de la doctrina original (Adv. Haer. III, 3,2). Cf. P. Grech, "Hermenéutica», en P. Rossano y otros., Nuevo Diccionario de Teología Bíblica ( Madrid 1990) 737. Original italiano 1988.

9 En este argumento seguimos de cerca, aunque con complementos, a A. A. Artola - J. M. Sánchez Caro, «Nacimiento y desarrollo de la conciencia canónica en el NT», en Nuevo Diccionario de Teología Bíblica, Biblia, 78-80. 
gentemente todo desde los orígenes, escribírtelo por su orden, ilustre Teófilo, ${ }^{4}$ para que conozcas la solidez de las enseñanzas que has recibido (Lc 1,1-4).

En estas palabras, el autor deja ver con claridad que antes de su obra ya existían otros escritos acerca de la vida y ministerio de Jesús, sobre todo de su Misterio Pascual (v.1). También, la existencia de la tradición referida al mismo misterio proveniente de testigos «oculares y servidores de la palabra» (v.2). En efecto, Lucas se propone poner a disposición de sus lectores, representados en la figura de Teófilo, esta misma tradición (v.3) habiéndola investigado y poniendo en orden el material reunido. Por ende, Lucas no pretende otra cosa sino poner por escrito la tradición apostólica, sirviéndose de su investigación y de las obras ya existentes. Su objetivo es proporcionar a los destinatarios de su obra una base sólida -segura y autorizada - para sustentar las enseñanzas que habían recibido (v.4).

En consecuencia, las consideraciones anteriores ponen a la luz una clara "conciencia canónica» en el autor del tercer evangelio. Su escrito persigue fundar la fe de los destinatarios con autoridad ${ }^{10}$.

Lo mismo puede argumentarse del primer final del cuarto evangelio: "Josús realizó en presencia de los discípulos otras muchas señales que no están escritas en este libro. ${ }^{31}$ Estas han sido escritas para que creáis que Jesús es el Cristo, el Hijo de Dios, y para que creyendo tengáis vida en su nombre (Jn 20,30-31)».

10 Cf. H. Schürmann, «Evangelienschrift und kirchliche Unterweisung. Die repräsentative Function der Schrift nach Lk 1,1-4», en Traditionsgeschichtliche Untersuchungen zu den Synoptischen Evangelien, Düsseldorf 1968, 251-271, especialmente el resumen final en la pág. 270: «Wir fassen zusammen: Im Vorstehenden konnten wir die Bedeutung einer Evangelienschrift für die kirchliche Unterweisung herausarbeiten, indem wir (I.) ihre unmittelbare und (II.) ihre mittelbare repräsentative Funktion an Hand von Lk 1,1-4 aufwiesen; Der Wert der Schrift liegt nicht darin, dass sie dem Glauben erst Inhalt und Gewissheit geben müsste -beides hat die kirchliche Unterweisung schon in sich. Aber es ist jedesmal ein Ereignis des Glaubens, wenn in der kirchlichen Unterweisung eine derartige „kanonische“ Schrift gelesen wird - weil dann nämlich die Glaubenden „überzeugt“ (und alle häretischen Gnostiker „überführt") werden von der apostolischen Paradosis und damit von den Heilsereignissen selbst. Eine Evangelienschrift ist somit ein Gnadenmittel, das uns in besonders unmittelbare Weise das apostolische Kerygma zubringt und damit mittelbar das Heil des gnadenvollen Christusgeschehens selbst über uns kommen lässt». 
El autor concluye su obra insinuando que todo el evangelio puede ser considerado como un libro de los signos que Jesús realizó ante sus discípulos. El v.30 refiere a los «discípulos» de Jesús así como Lc 1,2, a los «testigos oculares». Hace explícito que el escrito tiene por finalidad afianzar o suscitar ${ }^{11}$ en los destinatarios la fe en Jesús como Mesías e Hijo de Dios de modo que ellos, creyendo, tengan vida en él (v.31). Naturalmente, esta finalidad pone a la luz la profunda conciencia del autor del cuarto evangelio de estar dotado de la autoridad necesaria para escribir una obra que no solo transmite la verdadera fe en Jesús, sino también conduce en cierta medida a la vida. Este último aspecto subraya sobremanera la sacralidad que el autor da a su obra, pues «vida» es una de las formas con que se denomina la salvación ${ }^{12}$ en el cuarto evangelio, que en último término se identifica con Jesús mismo (cf. Jn 11,25).

La «conciencia canónica» se observa en escritos neo-testamentarios más recientes, incluso mucho más explícitamente que en los textos anteriores $^{13}$. El final de la segunda carta de Pedro:

11 A la luz de la tradición textual de Jn 20,31 se discute la finalidad del cuarto evangelio: "pero éstas se han escrito para que crean [ív $\pi i \sigma \tau \varepsilon v[\sigma] \eta \tau \varepsilon]$ que Jesús es el Cristo, el Hijo de Dios; y para que al creer, tengan vida en su nombre». En efecto, la partícula iv $v \alpha$ expresa finalidad. El contenido de la finalidad lo indica el verbo $\pi \imath \sigma \tau \varepsilon v[\sigma] \eta \tau \varepsilon$. Si la forma verbal incluye sigma $(\sigma)$ se trataría de un aoristo subjuntivo (lit. "para que creyesen o creyeran») y designa un hecho puntual en el pasado, aunque en ese caso debe interpretarse como aoristo ingresivo, esto es, el inicio del acto designado (es decir, = inicio de la fe): la finalidad del cuarto evangelio sería suscitar la fe a personas que no creen que Jesús es el Mesías y el Hijo de Dios. El cuarto evangelio pertenecería al ámbito del kerygma. Ahora bien, si la forma verbal no incluye sigma $(\sigma)$ se trataría de un presente del subjuntivo (lit. "para que crean») y en ese caso designaría una acción que continúa en el tiempo: la finalidad del cuarto evangelio sería consolidar o fortalecer la fe de los que ya creen que Jesús es el Cristo y el Hijo de Dios. En cuanto al soporte en los testimonios antiguos, B.M. Metzger, A Textual Commentary on the Greek New Testament (Stuttgart $\left.{ }^{4} 1994\right)$ 219-220, sostiene que sendas lecturas están respaldadas por testimonios muy antiguos, de modo que se hace difícil elegir entre ambas y, por eso, se decidió reflejarlas conjuntamente en el texto crítico publicado en ${ }^{27}$ Grundrisse zum Neuen Testament.

12 Son numerosísimas las citas al respecto. Cf. algunos ejemplos: Jn 1,4; 3,15-16; 4,$14 ; 6,33 ; 10,10-11$.

13 Seguimos la reflexión de A.A. Artola y J.M. Sánchez Caro, cf. n. 9. Vale la pena complementar y/o matizar estas reflexiones teniendo en cuenta las técnicas hermenéuticas usadas por los autores del Nuevo Testamentos; cf. P. Grech, 
${ }^{14}$ Por lo tanto, queridos, en espera de estos acontecimientos, esforzaos por ser hallados en paz ante él, sin mancilla y sin tacha. ${ }^{15} \mathrm{La}$ paciencia de nuestro Señor juzgadla como salvación, como os lo escribió también Pablo, nuestro querido hermano, según la sabiduría que le fue otorgada. ${ }^{16}$ Lo escribe también en todas las cartas cuando habla en ellas de esto. Aunque hay en ellas cosas difíciles de entender, que los ignorantes y los débiles interpretan torcidamente -como también las demás Escrituras- para su propia perdición (2Pe 3,14-16).

Se hace referencia a las cartas paulinas en general y se afirma que ellas son difíciles de entender y que no debe hacérseles una exégesis retorcida como a las «restantes Escrituras».

En la primera carta a Timoteo, el autor fundamenta sus enseñanzas citando como Escritura a Lc 10,7 y lo pone en paralelo con Dt 25,4, y sin diferencias considerables entre ellos: ${ }^{17}{ }^{17}$ os presbíteros que ejercen bien su cargo merecen doble remuneración, principalmente los que se afanan en la predicación y en la enseñanza. ${ }^{18} \mathrm{La}$ Escritura, en efecto, dice: No pondrás bozal al buey que trilla, y también: El obrero tiene derecho a su salario (1Tm 5,17-18)».

Así, queda clara la "conciencia canónica» del autor de la carta, al menos respecto del evangelio de Lucas, al que le atribuye una autoridad semejante a la de la Ley.

El final canónico de Marcos -Mc 16,9-2014 - también evidencia la conciencia canónica de los hagiógrafos tardíos del Nuevo Testamento, pues retoma resumidamente las apariciones del Resucitado que se narran en los otros evangelios canónicos. Así, el autor de la inserción canónica implícitamente reconoce la autoridad de todos ellos.

Con todo, es claro que los escritos neo-testamentarios designan bajo el rótulo de "Escritura» a los libros del AT, salvo la excepción de $1 \mathrm{Tm}$ 5,18 .

Hermenéutica, en P. Rossano y otros., Nuevo Diccionario de Teología Bíblica (Madrid 1990) 735-736. Original italiano 1988.

14 Mc 16,9-16 es un añadido posterior a Mc. De hecho, los mejores manuscritos del evangelio no lo reportan. Muy probablemente, el escrito haya sido un resumen de las apariciones del Resucitado que circulaba entre las iglesias primitivas, y haya sido agregado a Mc hacia el año $150 \mathrm{dC}$, debido a que esta obra original terminaba abruptamente sin narrar ningún encuentro de discípulos con Jesús resucitado. Cf. B. M. Metzger, A Textual Commentary, 102-107. 
CONCIENCIA CANÓNICA EN LA TRADICIÓN POST-APOSTÓLICA Y SU COMPRENSIÓN HISTÓRICA

La tradición post-apostólica desarrollará una reflexión explícita acerca de lo que hemos llamado "conciencia canónica»; es decir, el reconocimiento eclesial del carácter sagrado de los libros neo-testamentarios. También los designará explícitamente como «Escritura», análogamente como a los escritos sagrados hebreos. Esta reflexión doctrinal está en íntima relación con el desarrollo de la reflexión acerca de la inspiración bíblica. En efecto, la doctrina de la inspiración se refiere al carisma, recibido por los hagiógrafos, que explica que lo que ellos escribieron tenga a Dios por autor ${ }^{15}$. Otra doctrina en estrecha referencia a la comprensión del canon es el estudio sobre la verdad trasmitida por la Biblia, la cual también conoce una historia de su desarrollo, que en el pasado estuvo centrada en la discusión acerca de la inerrancia de la Biblia ${ }^{16}$.

Para alcanzar un entendimiento histórico más nítido de cómo la "conciencia canónica» se hizo cada vez más explícita en la reflexión de la Iglesia primitiva, es necesario tener presente que, hasta el final del siglo primero, los escritos cristianos no estuvieron a la disposición de todas (o de la mayoría) de las comunidades eclesiales. Solo paulatinamente, aunque siempre con mayor celeridad, se difundieron entre ellas durante las décadas iniciales del siglo segundo. El proceso fue sencillo y, precisamente por esa simplicidad, misterioso. En efecto, no se lo puede atribuir a una acción dirigida desde una cúpula eclesial central dotada de medios de hecho y de derecho para imponer unos determinados libros a todas las comunidades de la ecumene cristiana. De hecho, en aquella época remota ninguna comunidad eclesial disponía de medios suficientes como para imponer un determinado canon. El proceso fue, sin duda, dirigido por la acción del Espíritu Santo, cuyo influjo misterioso, ya en los orígenes de la Iglesia, conformó de un modo particular todo lo que ella necesitaba para cumplir su misión. Esta dirección se capta, por ejemplo, si se observa que no todos los escritos cristianos primitivos formarán parte del Nuevo Testamento. Así, por ejemplo, algunos escritos como el libro del Apocalipsis y la Segunda Carta de Pedro serán incluidos en el

15 Cf. M. A. Ferrando, Iniciación... , 133-156; V. Mannucci, La Biblia... , 119129; A. A. Artola - J. M. Sánchez Caro, Biblia... , 133-215.

16 Cf. M. A. Ferrando, Iniciación..., 157-175; V. Mannucci, La Biblia... , 225249; A. A. Artola - J. M. Sánchez Caro, Biblia..., 217-241. 
canon, pese a que, muy probablemente, su datación sea bastante tardía. En efecto, datan de alrededor del año $100 \mathrm{dC}$, coincidentemente con otros escritos cristianos que no entrarán en dicho canon, incluso a pesar de que su contenido sea ortodoxo, como, por ejemplo, la Didajé, el Pastor de Hermas y el Proto-evangelio de Santiago.

Con todo, esta dirección del Espíritu Santo no es extrínseca a la génesis de los escritos neo-testamentarios, sino precisamente intrínseca a ella -vinculada a la inspiración bíblica-; de modo que se la debe comprender en relación a la concesión a los hagiógrafos del carisma de la inspiración, por el cual ellos pusieron por escrito "todo y solo lo que Dios quería» ${ }^{17}$. Bajo el influjo del Espíritu Santo, las comunidades cristianas primitivas reconocieron ese carisma por varios caminos paralelos, los cuales muy pronto se entrecruzaron hasta llegar a una "conciencia» común de que todos esos escritos formaban una cierta unidad de sentido, dotada de autoridad para toda la comunidad eclesial. A esa unidad posteriormente se le llamó Nuevo Testamento.

Por eso, lo que las introducciones al Nuevo Testamento llaman "formación del canon» es en realidad un reconocimiento o toma de conciencia eclesial de una realidad que está en la génesis de los escritos neotestamentarios y que es posible rastrear en ellos. Así lo hemos mostrado en Lc 1,1-4; Jn 20,30-31 y en los demás textos citados anteriormente. Ahora procederemos a dilucidar algunos trazos de este proceso en la Primera Carta a los Tesalonicenses (1Ts) donde, a nuestro juicio, de un modo análogo que en los textos antes citados, queda plasmada también la "conciencia canónica» del autor de la epístola, el apóstol Pablo. Esos rasgos ciertamente eran manifiestos a los destinatarios de la carta y a las generaciones sucesivas que la conservaron y transmitieron como un escrito sagrado y autoritativo. También nos sirven a nosotros para entender su canonicidad.

\section{Conciencia canónica en la Primera Carta a los Tesalonicenses}

Leyendo 1 Ts encontramos dos pasajes, 4,15 y 5,27, en los cuales se deja ver claramente la conciencia de Pablo de estar trasmitiendo la Palabra del Señor en el escrito. Revisaremos a continuación ambos pasajes.

17 Cf. Dei Verbum 11. 
a) 1Ts 4,15: "Queremos decirles esto, como Palabra del Señor: los que vivamos, los que quedemos cuando venga el Señor, no precederemos

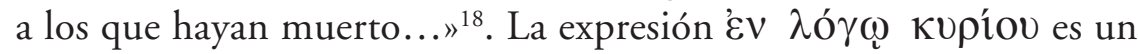
sintagma compuesto de la preposición ' $\mathcal{E} \mathrm{V}+$ un dativo que puede traducirse y/o entenderse de varias formas ${ }^{19}$ :

«Fundados en la Palabra del Señor». Así lo traducen algunas renombradas Biblias en español como, por ejemplo, la Biblia del Peregrino y el Libro del Pueblo de Dios. Esta traducción entiende la expresión ¿̇ $\lambda$ ó $\gamma \omega$ Kupíov como dativo instrumental ${ }^{20}$, esto es, «con la autoridad» de «la» o "una» palabra del Señor. Dependiendo de la extensión que se dé al complemento podría dar lugar, a su vez, a dos comprensiones de «Palabra del Señor».

La primera entiende "Palabra del Señor» como una referencia general al Evangelio comprendido, a su vez, como «el» mensaje de Jesús en sentido global. Con todo, esta primera interpretación choca con la literalidad de la expresión estudiada, pues en ella el sustantivo $\lambda$ ó yos carece de artículo. Por contraste, por ejemplo, en Col 1,5 leemos

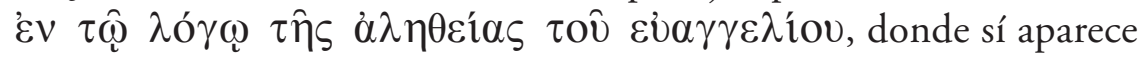
el artículo y, además, es explícita la identificación entre «Palabra de la verdad» y «el Evangelio». Lo mismo sucede en 1Ts 1,8, aunque con una construcción algo diferente. Pablo da cuenta del fruto maravilloso de su predicación a los tesalonicenses: "La Palabra del Señor»

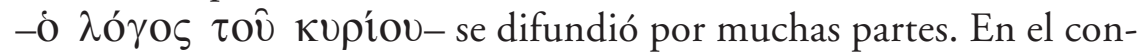
texto de 1Ts 1,2-10 es claro que «La Palabra del Señor» se identifica con «el Evangelio» predicado por el apóstol (v.5) que es también «la Palabra» abrazada por los tesalonicenses (v.6) ${ }^{21}$.

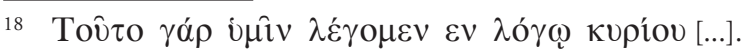

19 Cf. A.J. Malmerbe, The Letters to the Thessalonians. A New Translation with Introduction an d Commentary (Doubleday 2000) 267-269 propone tres posibles interpretaciones que se corresponden a las que expondremos. S. SCHreiber, "Eine neue Jenseitshoffung in Thessakiniki und ihre Probleme 1 Thess 4,13-18» (Bib 88 (2007) 328-334, especialmente 328-330, aborda estas interpretaciones y aporta en las citas a pie de página referencias a literatura relativamente reciente (cf. especialmente cita 9).

20 Cf. S. Schreiber, «Eine neue Jenseitshoffung», 330.

21 En 1Ts 2,13 se habla de "palabra escuchada de Dios» o «palabra de Dios», es decir, "palabra divina», precisamente por contraposición con la "palabra de hombres»,

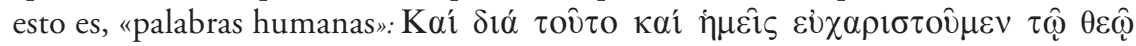


La segunda interpretación posible es atribuir a la expresión la función de introducción de una cita, directa o indirecta, de «una» palabra de Jesús pronunciada durante su ministerio terreno y conservada ya en otras tradiciones neo-testamentarias, ya solo en la tradición oral ${ }^{22}$. Así lo interpretan no pocos exégetas, los cuales discuten si la extensión de la cita se circunscribe solo a v.15b o si se extiende hasta el v.17. Estos estudiosos tienen en cuenta que existen otros lugares en el epistolario paulino donde el apóstol alude y/o cita palabras de Jesús durante su ministerio terreno, por ejemplo, 1Co 7,10-11; 9,14; 11,23-25. Para iluminar más detalladamente de dónde habría tomado Pablo la cita o alusión que trasmite en 1Ts 4,15b-17 (o solo en el v.15b), estos especialistas recurren a la comparación intra-bíblica de esos versículos con otros pasajes neo-testamentarios que contienen un mensaje similar. Por ejemplo, Mt 10,39; 16,25.28; Lc 12,30; Jn 5,25; 6,39-40, entre otros. También, utilizan el contraste del mensaje de los versículos en cuestión con las tradiciones apocalípticas intra- o extra-bíblicas. Usando estas operaciones exegéticas, los expertos llegan a diferentes soluciones. No abordamos la disparidad de esos resultados, porque nos desviaría de nuestro interés ${ }^{23}$.

J. Becker ${ }^{24}$ desestima esta última interpretación pues, en su opinión, la formulación de 1Ts 4,15 refleja la tradición de la comunidad an-

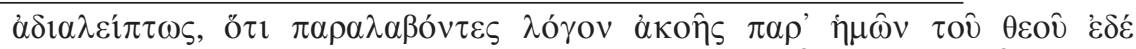

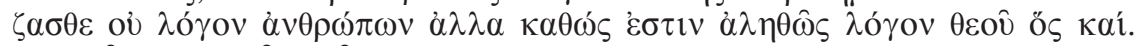

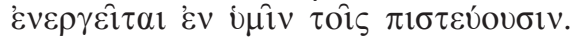

22 Cf. S. Schreiber, «Eine neue Jenseitshoffung», 329, cita 10 da los siguientes ejemplos: 1Co 11,23-25 recoge las palabras de Jesús de las institución recepcionadas también en Mc 14,22-24; Mt 26,26-28 y Lc 22,19-20; Rm 14,14 recoge una sentencia de Jesús acerca de lo puro e impuro que se recoge también en Mc 7,15 y Mt 15,11 y algo más lejana la expresión acerca del salario de los evangelizadores en 1Co 9,14 y Lc 10,7. Aunque le cuesta ver una relación semejante entre las expresiones acerca de la indisolubilidad del matrimonio en 1 Co 7,10.12, por un lado, y las de Mc 10,11-12; Mt 19,9 y Lc 18,8, por otro.

23 Cf. Malmerbe, Thessalonians, 267-269 presenta diferentes soluciones, aunque las relaciona estrechamente. S. SchreIber, «Eine neue Jenseitshoffung», 328-330 se inclina por considerar que se trata de la cita de una palabra del Señor. En concreto, estima que el v.15b es una especie de resumen paulino de la palabra de Jesús citada en los vv.16-17. Esta, por su parte, sería conocida por la tradición, aunque su forma precisa es desconocida (véase la cita 16 donde se incluye literatura reciente al respecto).

24 Cf. J. Becker, Pablo. El apóstol de los paganos, Salamanca 2007, 155. 
tioquena de la cual Pablo es portador. Esta afirmación encuentra su fundamento, siempre siguiendo al exégeta alemán, en el uso tanto de la primera persona plural "queremos decirles esto" o «los que quedemos», como de la referencia al Señor en tercera persona "cuando el Señor venga». Esa estructura sintáctica delataría que aquello que Pablo está comunicando son palabras pronunciadas conforme al carisma profético que ha recibido para la edificación de la comunidad. En otras palabras, el Señor glorificado habla a través del apóstol para la construcción eclesial (cf. 1Ts 2,6; cf. 2Co 10,8; 13,10 explícita-

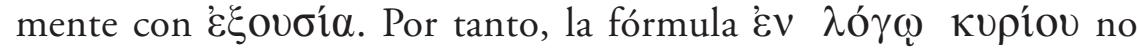
introduciría una referencia a palabras de Jesús terreno. Así pasamos al segundo modo de traducción y comprensión de la expresión.

"A modo de Palabra del Señor», "como Palabra del Señor». Así tra-

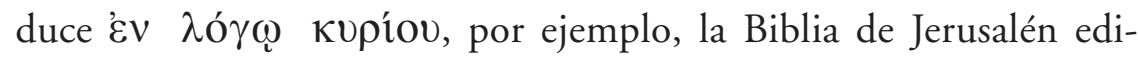
ción castellana. La fórmula pondría a la luz una declaración de tipo profético semejante a la pronunciada por el apóstol en 1Co 7,1025. Pablo afirmaría en ambos lugares que transmite la voluntad del Señor actuante en el hoy de la Iglesia. Esta manera de entender la expresión se apoya en la observación de que el apóstol hace la precisión que está por decir algo como palabra del «Señor»; es decir, de Cristo glorificado, y no de pronunciar unas palabras concretas de Jesús de Nazaret durante su ministerio terreno. Este modo de hablar, además, se rastrea en la tradición profética del Antiguo Testamento. En efecto,

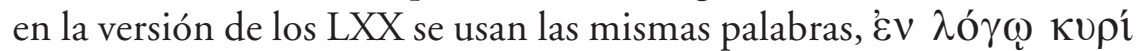
ov, en $1 \operatorname{Re} 20,35 ; 13,1.2 .5 .32 ; 2$ Cro 32,2 y Sir $48,3^{26}$, todos textos que, en mayor o menor medida, están situados en contextos relativos a la profecía. También '̇ $\lambda \hat{\varepsilon} \gamma \omega$ Kupíov está en directa relación con la expresión con que inician varios de los libros de los profetas «La palabra del Señor fue dirigida a...»: Jr 1,1; Ez 1,3; Os 1,1; Mi 1,1; Jon 1,1; Ag 1,1; Za 1,1 y expresiones semejantes en numerosos textos proféticos, como 2 Sam 24,11; $1 \operatorname{Re} 12.22 ; 13,20 ; 2 \operatorname{Re} 9,36 ; 15,12$; 20,19; Jon 3,1; Ag 1,3; 2,10.20: Za 1,7; 4,6.8; 6,9; Is 38,4 y no pocos pasajes de $\mathrm{Jr}(1,3.11 ; 13,3)$ y de $\mathrm{Ez}(3,16 ; 6,1 ; 7,1)$.

25 En contraste con 1Co 7,6.12.25 donde expresamente Pablo arguye que no trasmite preceptos del Señor. Cf. Malmerbe, Thessalonians, 267.

26 Cf. también $1 \operatorname{Re} 13,9.17$ y 2 Sam 16,23; 1Cro 15,15. 
Ahora bien, varios comentaristas de 1Ts 4,15-17 de todos los tiempos -desde un san Juan Crisóstomo hasta renombrados intérpretes del siglo pasado- estiman que el mensaje transmitido es la alusión a una palabra comunicada a Pablo por el Señor resucitado en una experiencia mística de revelación, semejante a otras que el apóstol tuvo a lo largo de su vida ministerial, según lo deja entrever en algunos lugares de su epistolario: Ga 1,12.16; 2,2; 1Co 2,10; 2Co 12,1.7; cf. Ef $3,3^{27}$. Sin embargo, en estos pasajes se describen las revelaciones con un lenguaje claramente profético y haciendo referencias explícitas a las comunicaciones recibidas por el apóstol de parte del Señor resucitado. Por contraste, en 1Ts 4,15-17 ese lenguaje y alguna referencia semejante no aparecen ${ }^{28}$.

¿Por qué en 1Ts 4,15 se manifiesta la «conciencia canónica» de Pablo respecto a la primera carta que escribe a los tesalonicenses? La respuesta es simple. Es claro que Pablo con la expresión estudiada no quiere solo dar importancia a la sentencia que la sigue en cuanto al origen de su contenido, se reduzca solo al v.15b o abarque además los vv.16 y 17, sino también manifiesta la autoridad profética de la cual el apóstol se siente revestido al hablar y comunicarse con los cristianos de aquella ciudad macedónica. Evidentemente que sí tiene autoridad para formular un pronunciamiento como "palabra del Señor», todo el escrito está premunido de la misma autoridad, aunque no quede de manifiesto expresamente en otros lugares del mismo.

b) $1 \mathrm{Ts}$ 5,27: «Les conjuro en nombre del Señor que hagan leer esta carta a todos los hermanos ${ }^{29}$ »

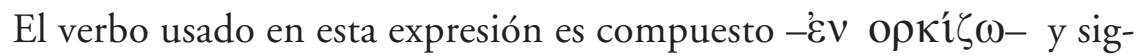
nifica: conjurar. La fórmula involucra una fuerte exhortación, pues implica hacer un juramento. Esta apreciación se confirma cuando se corrobora que la forma verbal es usada solo en este lugar en todo el

Aunque no pocos exégetas actuales prefieren pensar que Pablo tomó el contenido de 1 Ts 4,15-17 de la tradición apocalíptica judía. Cf. Malmerbe, Thessalonians, 268-269.

28 Cf. Schreiber, "Jenseitshoffnung...», 327.

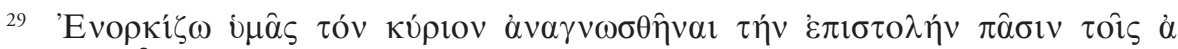

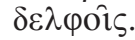


Nuevo Testamento y, además, forma parte de una construcción sintáctica al modo que el griego clásico construye los sintagmas de los verbos de juramento, donde aquel o aquello por el o lo que se jura se encuentra en acusativo sin preposición alguna ${ }^{30}$. La fórmula reviste, por tanto, una gran solemnidad. En el Nuevo Testamento, con todo, se usa la forma verbal simple afín o $\rho \kappa i ́ \zeta \omega$, incluso con idéntico complemento en acusativo, tal como en griego clásico (cf. Mc 5,7; Hch 19,13).

Pablo exhorta a sus comunidades en muchísimas ocasiones. De hecho, una de las características de sus cartas es incluir secciones parenéticas al final de ellas, precisamente antes de los saludos de despe$\operatorname{dida}^{31}$. También es bastante común que Pablo busque persuadir a los destinatarios de sus misivas, invocando al Señor como referente de sus exhortaciones. Así lo hace con gran solemnidad en 1Ts 5,27.

Encontramos una fórmula semejante a la de 1 Ts 5,27 en 1Ts 4,1:

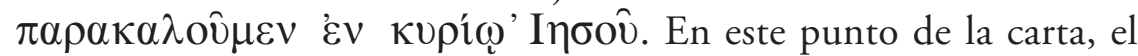
apóstol exhorta a sus destinatarios "en el Señor Jesús»" ${ }^{32}$ (cf. Ef 4,1733; 2 Ts $\left.3,12^{34}\right)$. Inmediatamente después puntualiza que su ministerio ha consistido en la transmisión de preceptos e instrucciones de parte del Señor Jesús (1Ts 4,235). Esta misma idea ya la había expresado un poco antes en la misma carta, aunque de una manera algo diferente: Pablo es capaz de exhortar a los tesalonicenses porque ha sido juzgado apto por Dios para predicar el Evangelio (1Ts 2,3-4). En efecto, la aprobación divina le ha dado la autoridad (lit: peso) específica de los apóstoles para transmitir el Evangelio (1Ts 2,6; cf. 2Co 10,8; 13,10)

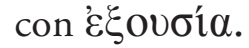

30 Cf. F. Blass - A. Debrunner, Grammatica del Novo Testamento (Brescia 1997) $149^{3}$ Original alemán 1976.

31 Cf. en las así llamadas cartas auténticas: Rm 12, 1-15, 13; 1Co 16, 1-18; Ga 5, 1-6, 10; Flp 3, 1b-4,9; 1Ts 4, 1-5, 22; Flm 8-22. Nótese la ausencia de una sección del género en $2 \mathrm{Co}$, probablemente se deba a la naturaleza compuesta de esta carta.

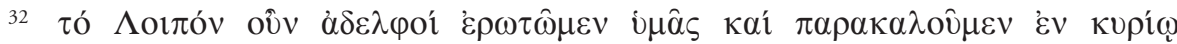
'Iпбov́.

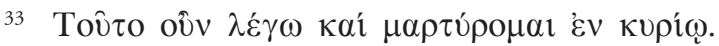

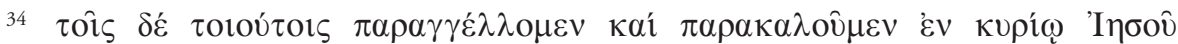
X $\rho\llcorner\sigma \tau \hat{\omega}$.

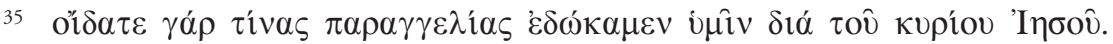


En otros lugares del epistolario, Pablo exhorta a los destinatarios de sus cartas con fórmulas similares a las de 1Ts 5,27: «por nuestro Señor Jesucristo" $\left(\mathrm{Rm} \mathrm{15}, 30^{36}\right)$; "por el nombre de nuestro Señor Jesucristo" (1Co $1,10^{37}$; 2Ts $\left.3,6^{38}\right)$; «por la mansedumbre y la benignidad de Cristo" (1Co 10,2 ${ }^{39}$ ); "por la misericordia de Dios» (Rm 12, $1^{40}$; cf. 2Co 5,20). También en otros sitios de sus cartas, el apóstol deja de manifiesto que trasmite preceptos y/o instituciones del Señor (cf. 1Co 7,10; 9,14; 11,23 [cf. 1Co 11,2; 15,3]; y por oposición 1Co 7,12; 25; 2Co 11,17). E incluso llama explícitamente a reconocer que lo que escribe es mandamiento del Señor en 1Co 14,37 (cf. Rm $15,15)$.

En atención a estas consideraciones, es razonable sostener que la fór-

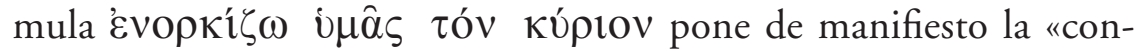
ciencia canónica» de Pablo al escribir 1Ts, esto es, poner a disposición de sus destinatarios un escrito que goza no solo de autoridad, sino también de una cierta sacralidad. Por eso, Pablo conmina su lectura a todos los hermanos apelando solemnemente al Señor.

En efecto, el contenido de la exhortación de 1Ts 5,27, «que se lea la carta a todos los hermanos»" ${ }^{41}$ recalca la "conciencia canónica» del apóstol expresada en la fórmula solemne que la introduce, pues lo que pretende con el «conjuro» es que todos los cristianos de Tesalónica reciban sus enseñanzas y preceptos directamente a través de la lectura y/o escucha de la carta. Así, Pablo hace de su misiva un medio de comunicación con autoridad.

Una exhortación semejante a la 1Ts 5,27 se encuentra en Col 4,16, aunque deja menos explícito el carácter sagrado de las cartas a las que se refiere. El autor llama a los colosenses a que la carta que tienen delante sea leída también en la comunidad cristiana de Laodicea y, al

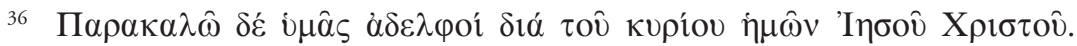

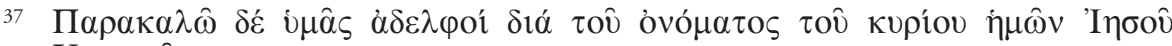

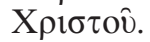

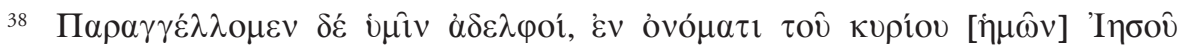
X

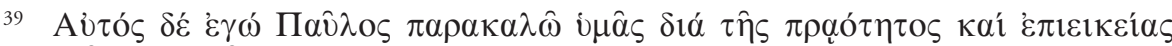
$\tau \mathrm{o} \hat{\mathrm{X}} \mathrm{X} \rho\llcorner\sigma \tau \mathrm{ov}$.

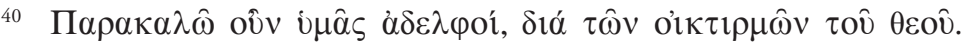

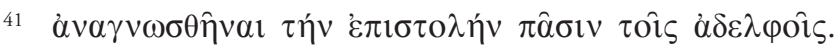


mismo tiempo, que la carta que ha enviado a esta última comunidad sea leída en Colosas.

En Flm $21^{42}$ y 2 Ts 3,14-15 ${ }^{43}$ encontramos indicaciones algo relacionadas con la exhortación de 1Ts 5,27. Pablo (y el autor de 2Ts, si esta carta fuera post-paulina) exige obediencia a los destinatarios de sendas misivas. Así deja en claro que supone que lo comunicado es exigible pues tiene autoridad sobre los destinatarios. En Flm 21 claramente respecto de Filemón. En 2Ts 3,14-15 va más allá, pues a quienes son dóciles a lo comunicado en la carta, les exige reaccionar severamente contra aquellos que no lo obedezcan, aunque en sentido medicinal y no definitivo. Por tanto, en Flm 21, como en 2Ts 3,1415 explicitan la autoridad del escrito en la misma línea de 1Ts 5,27, toda vez que la confianza de Pablo en Flm y la fuerte medida prescrita por él en 2Ts suponen que sendas cartas han sido leídas como escritos cuyo mensaje está revestido de autoridad y, por lo mismo, es exigible a sus destinatarios ${ }^{44}$.

También están relacionados con la indicación de 1Ts 5,27 aquellos lugares del epistolario paulino, donde el apóstol hace ver explícitamente que ha escrito una carta, o, al menos, la ha rubricado con su puño $^{45}$ : Ga 1,20; 6,11; Flm 19; cf. Col 4,18; 2Ts 3,17. La relación es evidente, estas indicaciones persiguen un propósito similar a la de 1 s 5,27; esto es, hacer notar a los destinatarios que la misiva que están leyendo proviene de la autoridad apostólica de Pablo. En este mismo sentido deben entenderse las referencias hechas por el apóstol a escritos suyos anteriores en algunas de sus cartas: 1 Co 5,9-11; 2 Co 1,13; 2,4.9; 7,12; Flp 3,1b (tal vez también Ef 3,3). En efecto, estas alusiones persiguen dar continuidad a la comunicación escrita actual,

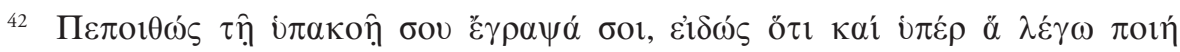

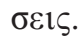

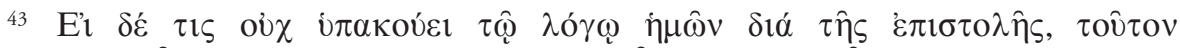

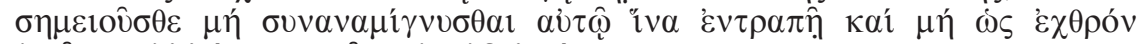

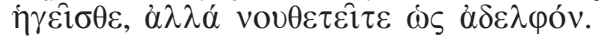

44 En este mismo sentido se entiende una de las últimas indicaciones del libro del Apocalipsis de Juan (cf. Ap. 22, 18-19).

45 Para el estudio de estos pasajes cf. C. Keith, "In My Own Hand": GraphoLiteracy and the Apostle Paul», (Bib 89 2008) 39-58 con abundante literatura al respecto. 
con otra anterior que sigue vigente y/o es necesario reinterpretar o actualizar a través de la presente (cf. 1Co 5,9-11).

\section{Conclusión}

La mostración de que Pablo deja trazos de la "conciencia canónica» con que escribe en el texto de 1 Ts pone de manifiesto que la canonicidad activa de aquella carta no es un elemento extrínseco a ella. En efecto, la canonicidad del escrito bíblico reclama la "conciencia canónica» de su autor, incluso aunque este no haya reflexionado explícitamente en ella. Solo por el hecho de que los autores bíblicos experimentaron el carisma de la inspiración como un don del Espíritu para la edificación de la Iglesia -en su caso para poner por escrito "solo y todo lo que Dios quería» (cf. Dei Verbum 11)-, pudieron trasmitir la Palabra de Dios en palabras humanas, llenas de autoridad, las cuales paulatinamente fueron siendo reconocidas como sagradas por las comunidades eclesiales. Esto es lo que ponen de manifiesto 1 Ts 4,15 y 5,27 respecto al íntegro contenido de toda la Primera Carta a los Tesalonicenses. 
Resumen: La canonicidad de los textos bíblicos es una propiedad intrínseca («canonicidad pasiva») que corresponde a la autoridad divina que los hagiógrafos les han impreso, gracias al carisma recibido del Espíritu Santo ("canonicidad activa»). La comunidad eclesial ha reconocido esta propiedad en un proceso histórico rico y complejo en tiempos primitivos del cristianismo. Este reconocimiento eclesial se refiere a la conciencia canónica ("canonicidad activa») que los autores bíblicos tuvieron al momento de componer sus obras y que la dejan ver o entrever en sus escritos. Ellos fueron conscientes de que transmitían palabras divinas en palabras humanas. El presente escrito intenta poner a la luz esta conciencia en Pablo respecto de 1Ts, para lo cual analiza pormenorizadamente dos pasajes de la carta.

Palabras clave: Pablo, Primera Carta a los Tesalonicenses, Canon, Canonicidad, Palabra de Dios, Inerrancia, Inspiración, Dei Verbum, Verbum Domini.

Abstract: The canonicity of the biblical texts is a quality of the texts themselves ("passive canonicity") depending on the inspiration their authors received from the Holy Spirit ("active canonicity"). The church communities acknowledged this quality of the texts during a historical process of early Christianity. This ecclesiastical recognition refers to the "active canonicity", that is, the conscience the authors had as they composed the writings that can be appreciated in the texts they wrote. They realized they were expressing divine meanings in human words. The present paper shows that conscience through two excerpts in Paul's 1 Thessalonians.

Keywords: Paul, 1 Thessalonians, Canon, Canonicity, Word of God, Inerrancy, Inspiration, Dei Verbum, Verbum Domini. 
